\title{
Characters recognition using keys points and convolutional neural network
}

\author{
M. Boutounte ${ }^{1}$, Y. Ouadid ${ }^{2}$ \\ ${ }^{1}$ National School of Business and Management, Ibn Zohr University, Dakhla, Morocco \\ ${ }^{2}$ Department of Computer Science Sultan, Faculty of Science and Techniques, Laboratory of Information Processing and \\ Decision and Support, Moulay Slimane University, Beni-Mellal, Morocco
}

\begin{tabular}{l} 
Article Info \\
\hline Article history: \\
Received Feb 1, 2021 \\
Revised Mar 29, 2021 \\
Accepted Apr 6, 2021 \\
\hline
\end{tabular}

\section{Keywords:}

Convolutional neural network Harris corner

Key point

Tifinagh OCR

\begin{abstract}
In this paper, the convolutional neural network $(\mathrm{CNN})$ is used in order to design an efficient optical character recognition (OCR) system for the Tifinagh characters. indeed, this approach has proved a greater efficiency by giving an accuracy of $99 \%$, this approach based in keys points detection using Harris corner method, the detected points are automatically added to the original image to create a new database compared to the basic method that use directly the database after a preprocessing step consisting on normalization and thinning the characters. Using this method, we can benefit from the power of the convolutional neural network as classifier in image that has already the feature. The test was performed on the Moroccan Royal Institute of Amazigh Culture (IRCAM) database composed of 33000 characters of different size and style what present the difficulty, the keys points are the same in the printed and handwritten characters so this method can be apply in both type with some modifications.
\end{abstract}

This is an open access article under the CC BY-SA license.

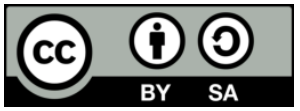

\section{Corresponding Author:}

Mehdi Boutaounte

National School of Business and Management

Ibn Zohr University

Dakhla, Morocco

Email: boutaounte.mehdi@gmail.com

\section{INTRODUCTION}

One of the most leading field of research is the optical character recognition, however the majority of research are targeting the popular language such as others languages like Latin and Arabic and ignoring others languages speaking by minority like amazigh which is a homito-semitic language coming from ancient Berber language. this language have so many variety of dialects from Morocco, Libya, Egypt, Tunisia and Mali. This language is spoken today by about 14 million people, mainly in the Maghreb. The tifinagh characters is normally written left to right and from top to bottom, it is a non cursive writing simplifying the segmentation of characters in a text image Amazigh. because of the similarity in shape of the characters and the there number (33 characters) the preprocessing time is very high, those characters present a challenge to research to create an efficient system for optical character recognition.

In this current paper, we first give a review of others proposed tifinagh characters recognition systems developed by others searchers such as, Bencharef et al. [1] used in feature extraction the riemannian metric these metric descriptors are reliable toward change scale. Boutaounte et al. [2] are using the simplest possible geometric elements (segments and key points) to create the graph and extracting the impact matrix [3] for recognition. Essaady et al. [4] who give a proposition used an analytical method used freeman coding for feature extraction and finite automation in recognition step. Ayachi et al. [5], [6] gived two methods for 
optical character recognition (OCR) system which used Moments invariants and Walsh transform for feature extraction, and the multilayer neuron networks and dynamic programming for the classification. In their work neural networks combined with walsh transform showed quite interesting results. Oujaoura et al. [7] proposed a system based on three features extractor GIST descriptors, texture, walsh, and bayesian networks in the classification for tifinagh characters recognition, but they have some problems in term of central processing unit (CPU) time and recognition rate. Amrouch et al. [8] used a directional feature vector sequence and continuous hidden markov models and these models are not a favoritism since each hidden markov models uses the learning of a single character, Zhiyi et al. [9], used Fuzzy pattern recognition in which they mainly classified each characters by methods according to maximum membership which posed a problem of recognition effecacity and in terms of processing time because of the descriptor vector size. Boutaounte et al. [10] presented an approach based on characters decomposition into multiples geometric shapes (segment, arc) by detecting the points of branch and end and using a comparison between different methods of classification such as neural network (NN), k-mean and support vector machines (SVM). Other work such as Wardani, [11] and Aharrane et al. [12] are based in the power of the convolutional neural network to build the OCR system, so the application of the convolutional neural network (CNN) or the deep learning in general are direct as other work in other language as the work of Finjan et al. [13] or El-Sawy et al. [14] applied in arabic language, Kadir et al, [15] used the CNN for number recognition in comparison with bag of features, Sadouk et al. [16] used a handwritten database but the recognition rate were between $95 \%$ and $98 \%$ but Benaddy et al. [17], used the CNN as a feature extractor and achieve a rate of $99 \%$.

All the realized works are using the features extraction and with a classifier like neural network or support vector machine, others are using the convolutional neural network as feature extractor or as classifier that gave good results, but the problem are the time to extract the features and to do the leaning phase and the rate of recognition that why we chose to create a new method that use directly image with keys points as features and the power of $\mathrm{CNN}$ as classifier to decrease the time and increase the rate. This paper is organized as follows: section 2 presents the techniques used to detect the keys points in each characters. The used $\mathrm{CNN}$ is presented in section 3. In the section 4 the experimental results and discussions are mentioned and then the conclusion.

\section{PROPOSED METHOD}

The preprocessing consists on binarization, normalization and thinning [18] the image in order to reduce the number of data used in the recognition section by keeping only the important information. Since our database is composed of monochrome images. The harris method [19] are used to detect the keys points which are added directly to the image before using a convolutional neural network (CNN) [20] to classify them.

\subsection{Normalization and thinning}

Normalization is a first step of pre-processing to remove the unwanted area and put the character in the center of the image. To do it, the vertical and horizontal histogram of the image are calculated to find the border of the character, (Figure 1). The horizontal and vertical histogram are scanned to find the corners of the characters Figure 2 illustrate an example of character image normalization.
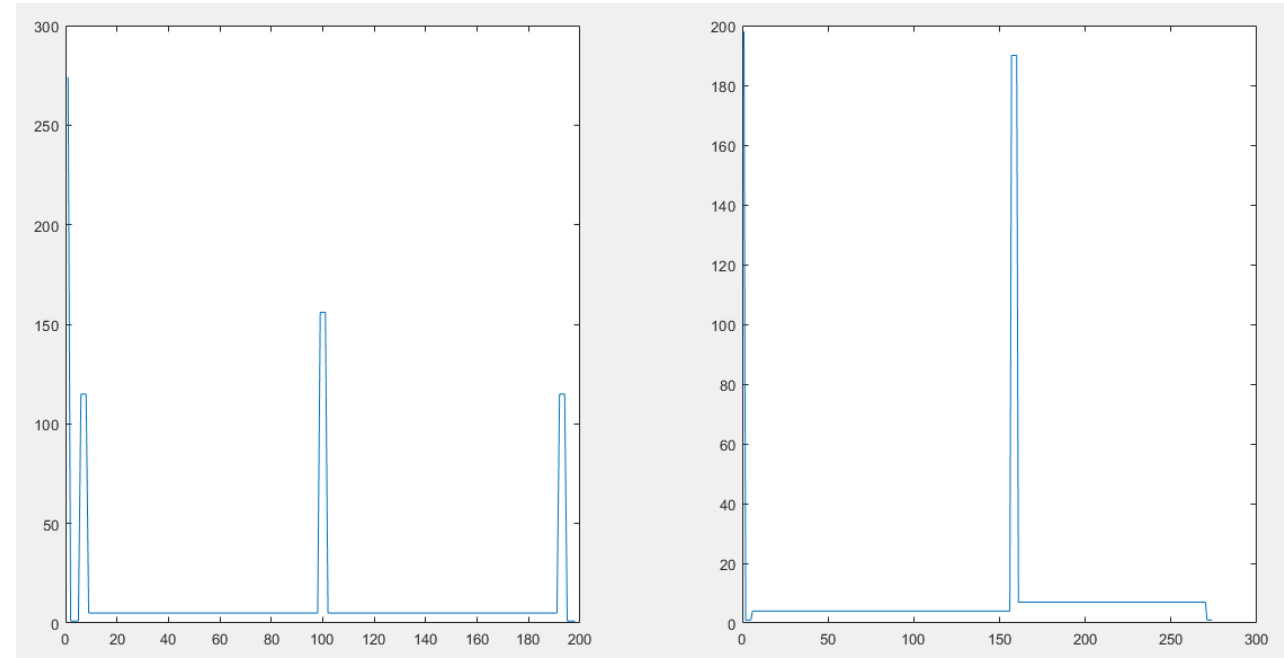

Figure 1. Vertical and horizontal histogram of the image 
Due to its robustness and speed the Zhang and Wang [21] algorithm is adopted. Which is a parallel algorithm that produces a perfect skeleton 8-connected in a single iteration and which operates the collisions. The proposed system for recognition is made up of three main phases in Figure 3, the pre-processing phase the normalization and thinning, the isolation of the character block by elimination of unused information and then the character recognition block. In other words, the preprocessing step, feature extraction and the recognition.

The this work the skeleton of the characters with the keys points is presented in the first step, and thereafter it will be transformed to geometric simple shape such as lines or arcs [22]. The goal is to provide a structural description of the character. First, the key points of the character are extracted using harris corner detector in Figure 4.

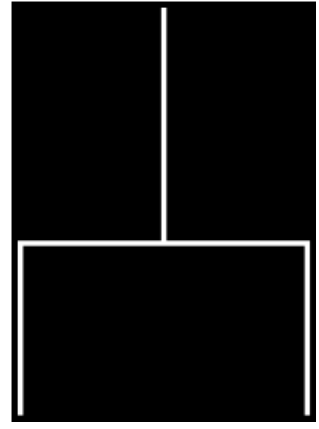

Figure 2. Result of normalization and thinning

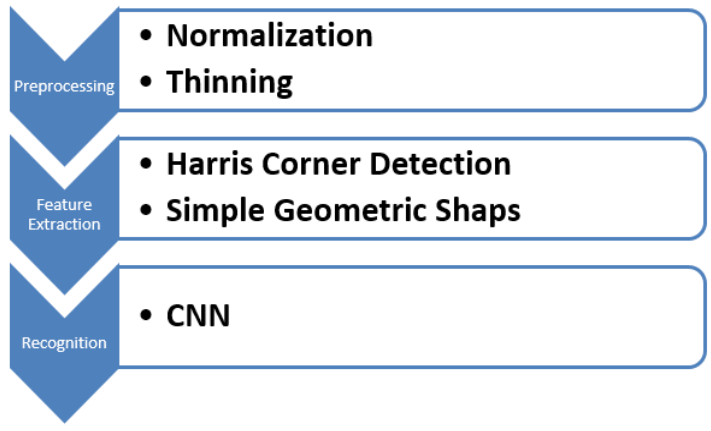

Figure 3. Tifinagh character recognition system

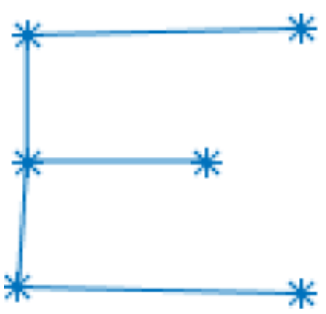

Figure 4. Key points detecter by harris method

The harris algorithm is an improvement of the moravec corners detector [23]. The principle of moravec algorithm is to consider a rectangular local window in the image to determine the average of the changes in the intensity in image by moving it to several directions. When the window undergoes a large sequence of change the minimum of it, is the corner or the point of interest. Assume that $\mathrm{I}$ is the intensity of the image, the changing $E$ produced by the movement $(x, y)$ is given by:

$$
E_{x, y}=\sum_{u, v} w_{u, v}\left|I_{x+u, y+v}-I_{u, v}\right|^{2}
$$

where,

$$
w_{u, v}=\exp -\left(u^{2}+v^{2}\right) / 2 \sigma^{2}
$$

The next step is distinct between the arc and segment, so for each two key points that are connected in the character, a segment is drawing between thereafter the distance among the drawing segment and the black pixels of the character that connect the two points in image is calculated. If the distance is equal to 0 it means that the geometric shapes between the two points are a simple segment, if not two possibly cases can be, first a simple geometrical shape in form of arc connected them or more than one connected segment due to an error in the method of segmentation in Figure 5.

In order to resolve this issue, the angle $\mathrm{Y}$ between the two key points and the point that have the biggest distance between the drawing segment and the black line that connect the key points is calculated and we set a threshold for this angle to determine the type of that geometric shapes. The Figure 6 shows the process of problem detection from the start to extracting the key points and also the simple geometric shapes [24]. The information collected in this step will be used to help the CNN in recognition step, a comparison was done between simple images and others with keys points to determine the utility of our method. 

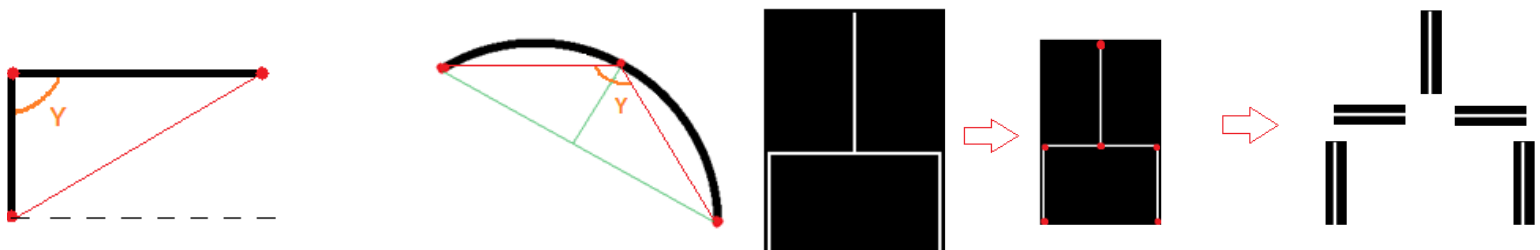

Figure 5. Determination of the $\mathrm{Y}$ angle to detect the segmentation error
Figure 6. Extracting key points and simple geometric shape

\section{EXPERIMENTAL RESULTS}

We tested our approach of Tifinagh character recognition on the database of IRCAM. This database includes 33000 characters printed in different sizes and writing styles. In Figure 7 each character will be treated to detect the keys points using haris corner method, the identification effected by a convolutional neural network. To improve the efficiency of our method, we use a CNN white two convolution layers and 2 pooling layers, the training process is performed on a personal computer (PC) equipped with Intel UHD Graphics 620 and a processor i7 8th generation, the accuracy obtained of training and testing is showed in the Table 1.

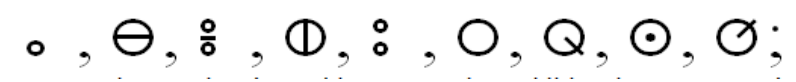

Figure 7. Similare character
Table 1. Accuracy

\begin{tabular}{ccc}
\hline Variable & Accuracy (\%) & Loss (\%) \\
\hline Simple method & 96.12 & 3.88 \\
Keys point method & 99.39 & 0.61 \\
\hline
\end{tabular}

The old method that uses feature extraction in tifinagh character recognition have several problems specially with character in Figure 7 that have a similarity of $80 \%$ or more, and to resolve the problem we need an additional treatment such as our previous work [25] or the recognition rate will be inferior to $95 \%$. In this paper this kind of problem was solved by adding key points. The difference between the simple method and the new method using the key points is close to $4 \%$ with an accuracy of $99 \%$. The Figures 8 and 9 are completing the table and showing the training progress of our $\mathrm{CNN}$ using the two methods.

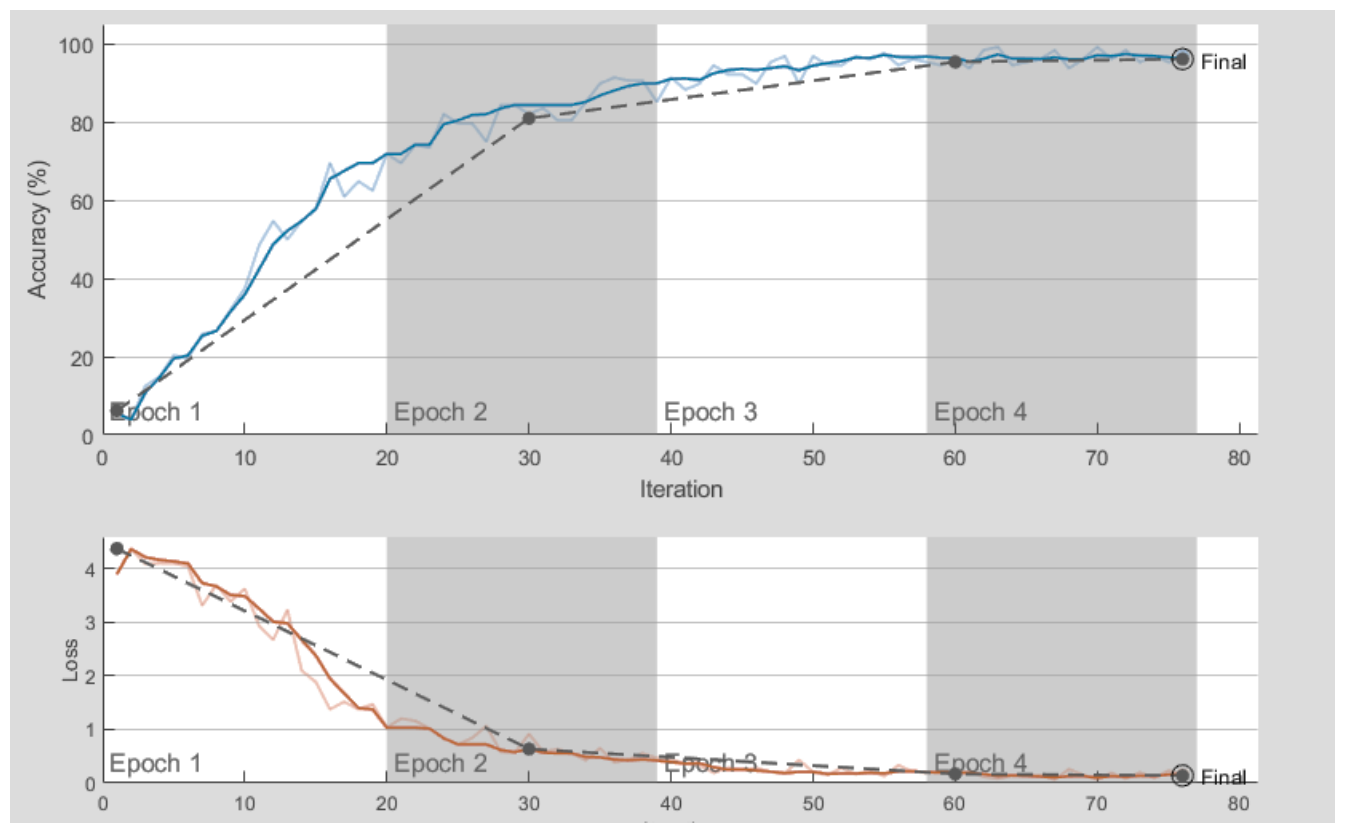

Figure 8. Accuracy and loss using the simple database 


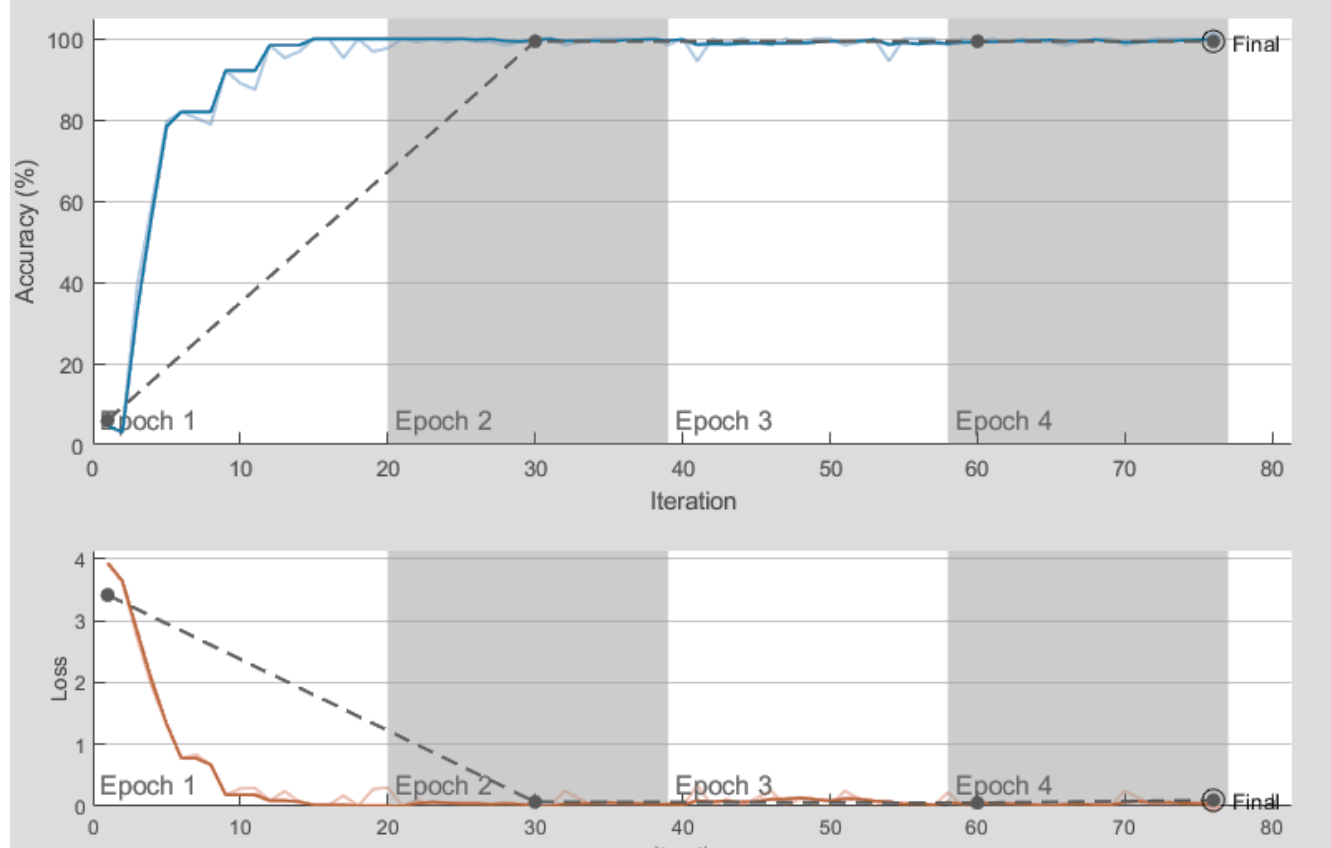

Figure 9. Accuracy and loss using the keys points database

\section{CONCLUSION}

In this work we presented a new technique for Tifinagh character recognition, using the key points and the geometric to correct the points detection error. The obtained results confirms that we have implemented an efficient method for characters recognition that can be used with other classifier, in future we can add more details to the characters image to improve the efficiency of the CNN, such as key points and types geometric shapes orientation. The obtained result are encouraging us to try this method on handwritten characters that need more preprocessing steps.

\section{REFERENCES}

[1] O. Bencharef, M. Fakir, N. Idrissi, B. Bouikhalen, and B. Minaoui, "Application of Riemannian geometry to Tifinagh character recognition in Française: Application de la géométrie riemannienne à la reconnaissance des caractères Tifinagh," Third international symposium on Automatic Amazigh processing (SITACAM'11), 2011.

[2] M. Boutaounte and Y. Ouadid; "Document Image Converter to XML File, Case of Tifinagh," International Journal of Computer Applications, vol. 145, no. 4, pp. 30-33, Jul. 2016, doi: 10.5120/ijca2016910569.

[3] D. Arrivault, "Contribution of Graphs to Unconstrained Recognition of Ancient Manuscript Characters in Française: Apport des Graphes dans la Reconnaissance Non-Contrainte de Caractères Manuscrits Anciens," Thesis, Université de Poitiers, Prancis, pp. 61, 2002.

[4] Y. Es Saady, A. Rachidi, M. El Yassa, and D, Mammass, "Printed Amazigh Character Recognition by a Syntactic Approach using Finite Automata," Journal of Graphics, Vision and Image Processing, vol. 10, no. 2, pp. 1-8, 2010.

[5] R. El Ayachi, M. Fakir, B. Bouikhalene, and S. Safi, "Offline printed amazighe scripts recognition," Journal of Theoretical and Applied Information Technology (JTAIT), vol. 20, no. 2, 2010.

[6] R. El Ayachi, M. Fakir, and B. Bouikhalene, "Recognition of Tifinagh Characters Using Dynamic Programming \& Neural Network," Book of Document Recognition and Understanding (InTech), pp. 35-57, 2011, doi: $10.5772 / 16278$.

[7] M. Oujaoura, B. Minaoui, and M. Fakir, "Walsh, Texture and GIST Descriptors with Bayesian Networks for Recognition of Tifinagh Characters," International Journal of Computer Applications (IJCA), vol. 81, no. 12, pp: 39- 46, 2013, doi: 10.5120/14068-2464.

[8] M. Amrouch, Y. Es-saady, A. Rachidi, M. El Yassa, and D. Mammass, "Handwritten Amazigh Character Recognition System Based on Continuous HMMs and Directional Features," International Journal of Modern Engineering Research (IJMER), vol. 2, no. 2, pp. 436-441, 2012.

[9] R. Zhiyi, Z. Ying, H. Dongming, and W. Lurong, "Visualization of License Plate Recognition System," Indonesian Journal of Electrical Engineering and Computer Science (IJEECS), vol. 11, no. 11, pp: 6714-6721, 2013, doi: 10.11591/telkomnika.v11i11.3520. 
[10] M. Boutaounte and Y. Ouadid, "Tifinagh Characters Recognition Using Simple Geometric Shapes," Indonesian Journal of Electrical Engineering and Computer Science (IJEECS), vol 3, no. 1, pp:235-239, 2016, doi: 10.11591/ijeecs.v3.i1.pp235-239.

[11] N. Aharrane, A. Dahmouni, K, El Moutaouakil, and K. Satori, "Printed Tifinagh script recognition from Web and natural scenes images in multilingual environment," TICAM'18, Nov. 2018.

[12] D EL Wardani, "Tifinagh-IRCAM Handwritten character recognition using Deep learning," arXiv:1912.10338, Dec. 2019

[13] F. R. Hasan, A. S. Rasheed, A A. Hashim, and M. Murtdha, "Arabic handwritten digits recognition based on convolutional neural networks with resnet-34 model," Indonesian Journal of Electrical Engineering and Computer Science (IJEECS), vol. 21, no. 1, pp. 174-178, Jan. 2021, doi: 10.11591/ijeecs.v21.i1.pp174-178.

[14] A. El-Sawy, M. Loey and H. EL-Bakry, "Arabic Handwritten Characters Recognition using Convolutional Neural Network," WSEAS Transactions on Computer Research, vol. 5, no. 1, pp. 11-19, 2017.

[15] N. H. M. Kadir, S. N. S. M. N. Hidayah, M. Norasiah, and I. Zaidah, "Comparison of convolutional neural network and bag of features for multi-font digit recognition," Indonesian Journal of Electrical Engineering and Computer Science (IJEECS), vol. 15, no. 3, pp. 1322-1328, 2019, doi: 10.11591/ijeecs.v15.i3.pp1322-1328.

[16] L. Sadouk, T. Gadi, and E. Essoufi, "Handwritten tifinagh character recognition using deep learning architectures," Proceedings of the 1st International Conference on Internet of Things and Machine Learning, 2017, pp. 1-11.

[17] M. Benaddy, O. El Meslouhi, and M. Kardouchi, "Handwritten Tifinagh Characters Recognition Using Deep Convolutional Neural Networks," Computer Science Sensing and Imaging (CSSI), Mar. 2019, doi: 10.1007/s11220-019-0231-5.

[18] R. C. Gonzalez and R. E. Woods, Digital Image Processing Using MATLAB, Gatesmark Publishing, Jan. 2020.

[19] C. G. Harris and S. Mike, "A Combined Corner And Edge Detector," Alvey Vision Conference, vol. 15, no. 50, 1988.

[20] D. Ciregan, U. Meier, and J. Schmidhuber, "Multi-column deep neural networks for image classification," 2012 IEEE Conference on Computer Vision and Pattern Recognition, 2012, pp. 3642-3649, doi: 10.1109/CVPR.2012.6248110.

[21] T. Y. Zhang, and C. Y. Suen, "A Fast Parallel Algorithm for Thinning Digital Patterns," Communications of the ACM, vol. 27, no. 3, pp. 236-239, 1984, doi: 10.1145/357994.358023.

[22] Y. Ouadid, M. Fakir, and B. Minaoui, "Tifinagh Printed Character Recognition through Structural Feature Extraction”. International Journal of Computer Vision and Image Processing, vol. 6, no. 2, pp: 42-53, 2016, doi: 10.4018/IJCVIP.2016070103.

[23] H. Moravec, "Obstacle Avoidance and Navigation in the Real World by a Seeing Robot Rover," Dissertation, Robotics Institute, Carnegie-Mellon University, Pittsburgh, USA, 1980.

[24] Y. Ouadid, B. Elbalaoui, M. Boutaounte, M. Fakir, and B. Minaoui, "Handwritten tifinagh character recognition using simple geometric shapes and graphs," Indonesian Journal of Electrical Engineering and Computer Science (IJEECS), vol. 13, no. 2, pp :598-605, 2016, doi: 10.11591/ijeecs.v13.i2.pp598-605 .

[25] Y. Ouadid, M. Boutaounte, M. Fakir, and B. Minaoui, "Tifinagh Character Recognition using Harris Corner Detector and Graph Representation," International Journal of Computer Applications (IJCA), vol. 149, no.3, pp. 17-23, Sep. 2016, doi: 10.5120/ijca2016911366. 